\title{
Generation of Unfolded DNA in Human Neutrophils Following Hypothermal Treatment
}

\author{
Jin Kawata ${ }^{1,2}$, Makoto Kikuchi ${ }^{2}$, Hisato Saitoh ${ }^{{ }^{*}}$ \\ ${ }^{1}$ Department of New Frontier Sciences, Graduate School of Science and Technology, Kumamoto University, Kumamoto, Japan \\ ${ }^{2}$ Kumamoto Health Science University, Kumamoto, Japan \\ Email: " hisa@kumamoto-u.ac.jp
}

Received April 27, 2013; revised May 25, 2013; accepted June 8, 2013

Copyright (C) 2013 Jin Kawata et al. This is an open access article distributed under the Creative Commons Attribution License, which permits unrestricted use, distribution, and reproduction in any medium, provided the original work is properly cited.

\begin{abstract}
By visualizing DNA with diamidino phenylindole (DAPI), we found that hypothermal incubation followed by rewarming of human neutrophils resulted in an increased number of DAPI-positive objects representative of extensive DNA unfolding seemingly similar to neutrophil extracellular traps (NETs). In contrast to canonical NET formation, diphenylene iodonium (DPI), an NADPH oxidase inhibitor, exhibited negligible effects on formation of the DAPI-positive objects. Moreover, multiple instances of DNA damage were detected in the objects, but not in canonical NETs. Our results thus suggest the potential of hypothermia for triggering DNA structural alteration in neutrophils, which is similar to but distinct from NET formation.
\end{abstract}

Keywords: Hypothermal Treatment; DNA Unfolding; Neutrophil Extracellular Trap (NET)

\section{Introduction}

Low-temperature conditions, referred to as hypothermia, are generally used for the storage of cells, tissues, organs and bodies for both scientific and clinical purposes. Hypothermia is an important means of slowing down cellular metabolism during storage, thus inhibiting injurious processes caused by the deficiency of oxygen and substrate supply. However, hypothermia can give rise to cell injury, including cell death [1,2].

Neutrophils are a main type of effector cell in the innate immune system $[3,4]$, which circulate in the blood and engulf invading microorganisms such as bacteria and fungi by phagocytosis. In addition to such activities, Brinkmann et al. have reported that, following activation by microorganisms, neutrophils can undergo morphological changes detectable by microscopic observations [5]. These changes include loss of the lobular-shaped nucleus followed by disintegration of the nuclear envelope, which allow nuclear, cytoplasmic and granular components to mix together and subsequently rupture the cell membrane to release the DNA/chromatin into the extracellular environment [5]. The result is that the unfolded DNA/chromatin fibers with attached bactericidal proteins can function as neutrophil extracellular traps (NETs) for microorganisms. NETs appear to be the result

"Corresponding author. of a unique form of cell death. Therefore, as opposed to apoptosis and necrosis, Steinberg and Grinstein coined the term "NETosis" for neutrophil cell death, which leads to the formation of NETs [6].

In addition to microorganism infection, several physiological inducers of NETs have been reported [7 and references herein]. For instance, platelets activated via Tolllike receptor 4 rapidly induce NET formation [8]. Antibodies [9], antibody-antigen complexes [10,11], human immunodeficiency virus (HIV-1) [12], and microbial components such as lipopolysaccharide [13,14] are also known to induce the formation of NETs. Although the intracellular signaling pathway(s) that transmit these physiological stimuli remain largely unknown, reactive oxygen species (ROS) generation was demonstrated to be an absolute requirement for NET formation $[15,16]$. Thus, one of the most widely-used agents to induce NETs in in vitro experiments is phorbol-12-myristate-13-acetate (PMA), which directly stimulates protein kinase $\mathrm{C}$ (PKC) leading to potent activation of nicotinamide adenine dinucleotide phosphate (NADPH) oxidase, which in turn generates superoxide $[5,7,17]$. Therefore, it is reasonable to use diphenylene iodonium (DPI), a NADPH oxidase inhibitor [18], to block the formation of PMA-stimulated NETs $[15,17,19]$.

In this study, we found that hypothermal incubation of 
human neutrophils at $4^{\circ} \mathrm{C}$ for up to $1 \mathrm{~h}$ followed by incubation at $37^{\circ} \mathrm{C}$ resulted in an increased number of DAPI-stainable objects similar to global DNA unfolding observed in PMA-stimulated NETs. However, our additional experimental data revealed that hypothermia/rewarming-induced DNA unfolding was regulated in a manner similar to, but biochemically and pharmacologically distinct from, canonical NETs. Although the molecular mechanism of this phenomenon is not fully understood, we inferred, based on our experimental data, the possible role of ROS, which were generated during hypothermia/rewarming-treatment in a manner independent of NADPH oxidase activity in the formation of the DAPI-positive, NET-like objects.

\section{Materials and Methods}

\subsection{Peripheral Blood Preparation and Culture}

Human peripheral blood preparations (from two normal male donors, collected in compliance with Kumamoto Health Science University and approved by the University Oversight Committee) were enriched for neutrophils by density gradient centrifugation with HISTOPPAQUE 117 (Sigma-Aldrich) and Lymphocyte Separation Solution 1.119 (Nakarai Tesque) according to the procedures described by the supplier. Washed enriched neutrophilic fractions were counted and examined for purity using Wright Giemsa staining (Sigma-Aldrich).

\subsection{Drug and Hypothermal Treatments}

Cells were incubated in culture dishes containing an immersed coverslip in RPMI 1640 (Sigma-Aldrich) supplemented with 5\% fetal bovine serum (FBS), 1\% penicillin/streptomycin and $0.1 \%$ gentamaycin in a humidified atmosphere containing $5 \% \mathrm{CO}_{2}$. To induce NETs, PMA (Wako Pure Chemical Industries) was added to the culture medium at a concentration of $50 \mathrm{nM}$ and incubated for $4 \mathrm{~h}$ at $37^{\circ} \mathrm{C}$. To inhibit NADPH oxidase activity, DPI (Cayman Chemical) was added to the culture medium at a concentration of $20 \mu \mathrm{M}$. Hypothermal treatment and rewarming of cells were performed by incubation in a humidified atmosphere containing $5 \% \mathrm{CO}_{2}$. After drug and/or hypothermal/rewarming treatment, the coverslips were removed from the cultures and subjected to appropriate assays. DNA was visualized by staining with DAPI.

\subsection{Antibodies and Immunostaining}

Cells were washed once for 5 min with ice-cold PBS and then fixed with 4\% paraformaldehyde in PBS for $5 \mathrm{~min}$ at room temperature. After fixation, the cells were rinsed once with PBS and subjected to indirect-immunofluorescence analysis using anti-neutrophil elastase (Calbio- chem), anti-histone H3 (Santa Cruz Biotechnology), and anti-histone H3 citrulline R26 (Abcam) antibodies. The secondary antibodies were obtained from Santa Cruz Biotechnology and Sigma-Aldrich.

\subsection{Bacteria Trapping Assay}

Escherichia coli BL21 (DE3) were transformed with pET28-EGFP, a plasmid for expression of green fluorescent protein (GFP), and cultured in Luria-Bertani (LB) medium containing kanamycin at $37^{\circ} \mathrm{C}$ for $16 \mathrm{~h} \cdot 10^{7} \mathrm{E}$. coli cells were incubated with a coverslip containing hypothermia/rewarming-induced DAPI-positive objects in RPMI 1640 supplemented with 5\% FBS at $37^{\circ} \mathrm{C}$. After $20 \mathrm{~min}$ at room temperature, the coverslips were washed three times with PBS followed by incubation with 4\% paraformaldehyde. DNA fibers were stained with DAPI. Because the E. coli expressed GFP, bacteria trapped by DNA fibers could be detected by fluorescence microscopy. For DNase I treatment, the coverslips were treated with PBS containing $100 \mathrm{U} / \mathrm{ml}$ DNase I (Takara) at $37^{\circ} \mathrm{C}$ for $1 \mathrm{hr}$. The numbers of $E$. coli with GFP signals on the coverslips were counted by fluorescent microscopy.

\subsection{TUNEL Assay}

Terminal deoxynucleotidyl transferase dUTP nick end labeling (TUNEL) assays were performed using the MEBSTAIN Apoptosis TUNEL Kit II (MBL) according to the manufacturer's instructions. The TUNEL-positive cells were counted under a microscope. The percentage of TUNEL-positive cells was defined by the number of positive cells among the total number of cells in each sample. For one experiment, cells were counted in at least three different microscopic fields of view.

\subsection{Intracellular ROS Detection Assay}

Intracellular ROS production was monitored using the cell permeable fluorescent dye, CellROX Deep Red Reagent (Invitrogen). This agent can readily react with ROS to form a fluorescent product proportional to the amount of ROS generated in the cells. The cells were incubated with $5 \mu \mathrm{M}$ CellROX Deep Red for $30 \mathrm{~min}$ and then harvested. The fluorescence intensity of the cells was measured using a FACSVerse flow cytometer (BD Biosciences).

\subsection{MitoTracker Analysis}

After fixation with $4 \%$ paraformaldehyde, cultured human neutrophils were stained with the mitochondrionspecific dye, MitoTracker Red CMXRRos (Invitrogen), according to the manufacturer's instruction. The cells were immediately analyzed using a FACSVerse flow cytometer. 


\subsection{Statistical Analysis}

Unless otherwise stated, all data are presented as the mean \pm SD. Within individual experiments, data points were based on a minimum of triplicate representative samples and experiments were repeated at least three times.

\section{Results and Discussion}

\subsection{Effect of Hypothermia on Human Neutrophils in Culture}

After isolating human neutrophils from peripheral blood preparations (see Materials and Methods), the cells $(4.5 \times$ $10^{6}$ cells) were incubated at $4^{\circ} \mathrm{C}$ for $1 \mathrm{~h}$ followed by incubation at $37^{\circ} \mathrm{C}$ for $5 \mathrm{~h}$ in the 6 -cm culture dish supplemented with $2 \mathrm{ml}$ of the culture medium, in which a coverslip was immersed (Figure 1(a)). We found that most of the cells were present as non-adherent forms, and were thus floating in the culture medium. These non-adherent cells appeared morphologically intact as shown by

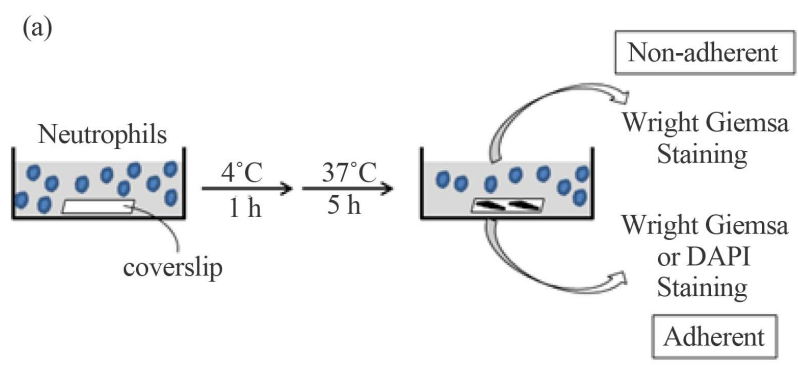

(c)
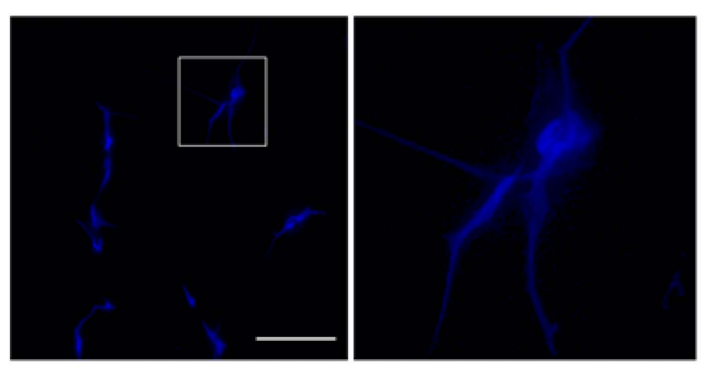

Wright-Giemsa staining (Figure 1(b), left panel). In contrast, we unexpectedly found that small, but substantial, numbers of Wright-Giemsa-stainable materials, which looked different from intact neutrophils, were present on the coverslip (Figure 1(b), right panel).

When the materials on the coverslip were stained with DAPI without any fixative treatment, we observed bright fluorescent signals under fluorescent microscopy, many of which appeared to consist of multiple DAPI-positive strings (Figure 1(c)). Because DAPI is a fluorescent dye that intercalates into double-stranded DNA, and that living neutrophils are less permeable to the dye than dead neutrophils, we thought it probable that these bright DAPI-stained signals represented global DNA unfolding of dead neutrophils, which somehow adhered to the coverslip. It should be mentioned that there were few neutrophils with normal morphology on the coverslip per view field, implying that most of neutrophils floated in the culture medium under the standard culture conditions.

(b)
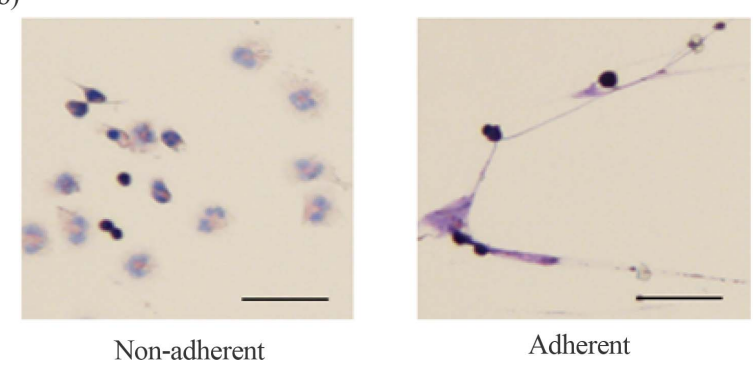

(d)

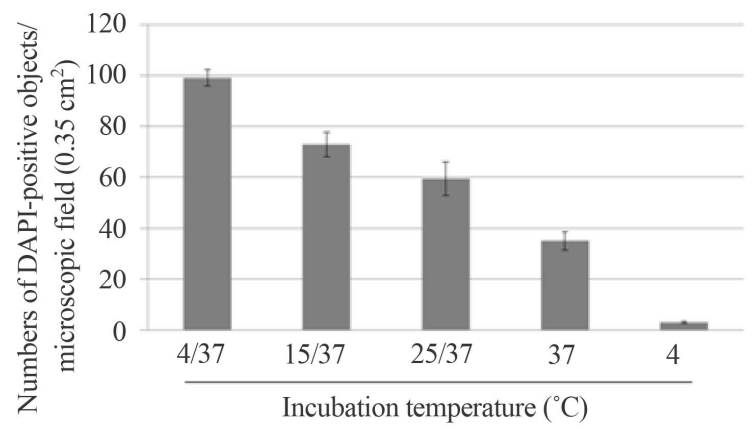

Figure 1. DAPI-stained objects in the hypothermia/rewarming-treated human neutrophils. (a) Schematic representation of procedure for detecting the hypothermia/rewarming-induced DAPI-positive objects. Human neutrophils from peripheral blood preparations were cultured in dishes containing a coverslip at $4{ }^{\circ} \mathrm{C}$ for $1 \mathrm{~h}$ followed by rewarming at $37^{\circ} \mathrm{C}$ for $5 \mathrm{~h}$. Non-adherent and adherent materials in the culture medium stained with Wright Giemsa; (b) Non-adherent and adherent materials in the culture were stained with Wright Giemsa (left and right panels). Bar indicates $50 \mu$ m; (c) The morphologies of the DAPI-stained objects adherent to the coverslip were detected by fluorescence microscopy (left panel). Bar indicates 50 $\mu \mathrm{m}$. The panel on the right shows a higher magnification of the region indicated in the left panel; (d) Human neutrophils from peripheral blood preparations $\left(1 \times 10^{6}\right.$ cells) were cultured in dishes containing a coverslip for $6 \mathrm{~h}$ at $4^{\circ} \mathrm{C}(4)$, at $4^{\circ} \mathrm{C}$ for $1 \mathrm{~h}$ followed by rewarming at $37^{\circ} \mathrm{C}$ for $5 \mathrm{~h}(4 / 37)$, at $15^{\circ} \mathrm{C}$ for $1 \mathrm{~h}$ followed by rewarming at $37^{\circ} \mathrm{C}$ for $5 \mathrm{~h}(15 / 37)$, at $25^{\circ} \mathrm{C}$ for 1 $\mathrm{h}$ followed by rewarming at $37^{\circ} \mathrm{C}$ for $5 \mathrm{~h}(25 / 37)$, and at $37^{\circ} \mathrm{C}$ for $6 \mathrm{~h}(37)$. After incubation under the conditions as indicated, the numbers of DAPI-positive objects on the coverslips in the microscopic field $\left(0.35 \mathbf{c m}^{2}\right)$ were counted. The values shown represent means $\pm \mathrm{SE}$ of three independent experiments. 
We then investigated whether the requirement for DAPI-positive object production was simple exposure to hypothermia or rather the combination of hypothermia/ rewarming. When human neutrophils were maintained at a constant temperature of either $4^{\circ} \mathrm{C}$ or $37^{\circ} \mathrm{C}$, significantly less DAPI-positive signals were detected as compared with cells cultured either at $4^{\circ} \mathrm{C}, 15^{\circ} \mathrm{C}$, or $25^{\circ} \mathrm{C}$ for $1 \mathrm{~h}$ followed by incubation at $37^{\circ} \mathrm{C}$ for $5 \mathrm{~h}$ (Figure 1(d)). These results suggest that the appearance of the DAPIpositive objects was associated with incubation of neutrophils under hypothermal conditions followed by rewarming.

\subsection{Comparison of the Biochemical and Immunohistochemical Properties of Hypothermia/Rewarming-Induced DAPI-Positive Objects and PMA-Stimulated}

When we observed the DAPI-positive objects in hypothermia/rewarming-treated human neutrophils, we noticed that morphological similarities between the objects and DAPI-stained PMA-stimulated NETs, leading us to suspect that the DAPI-positive objects per se might represent NETs (Figure 2(a)). To investigate this possibility, we first asked whether the that DAPI-positive objects possessed the ability to bind bacteria. Given NETs are defined as extracellular DNA-proteinaceous structures that exhibit the ability to associate with a wide variety of Gram-positive and Gram-negative pathogens [7], we expected that the DAPI-positive structures might also show similar properties. As shown in Figure 2(b), when GFP-expressing E. coli was incubated with the coverslip containing DAPI-positive objects, we found multiple GFP signals present together with the DAPI-signals. Their ability to trap bacteria appeared equivalent to that of PMA-stimulated NETs, because the number and distribution of GFP-signals associated with the DAPI-positive objects were very similar to those associated with PMA-stimulated NETs, suggesting that the objects possessed the ability to trap bacteria. It should be mentioned that the number of bacteria trapped to the DAPI-positive objects was reduced when the coverslips were treated with DNase I (Figure 2(c)). Similar results were obtained when PMA-stimulated NETs were treated with DNase I. These results imply that both structures are equally susceptible to DNase I treatment with respect to bacterial trap.

To further evaluate the similarities between the DAPIpositive objects and canonical NETs, we performed indirect-immunofluorescence analysis using antibodies that recognize marker proteins for NETs: anti-neutrophil (a)

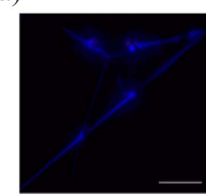

$4^{\circ} \mathrm{C} / 37^{\circ} \mathrm{C}$

(b)

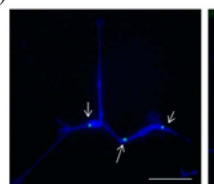

$4^{\circ} \mathrm{C} / 37^{\circ} \mathrm{C}$

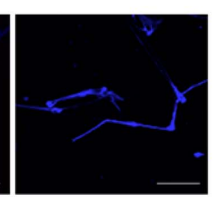

PMA

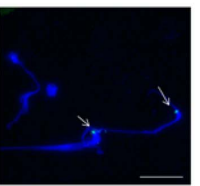

PMA (c)

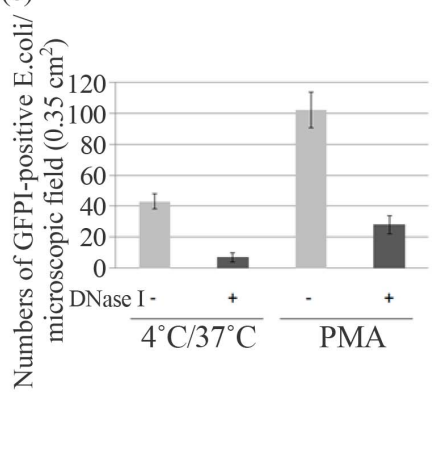

(d)
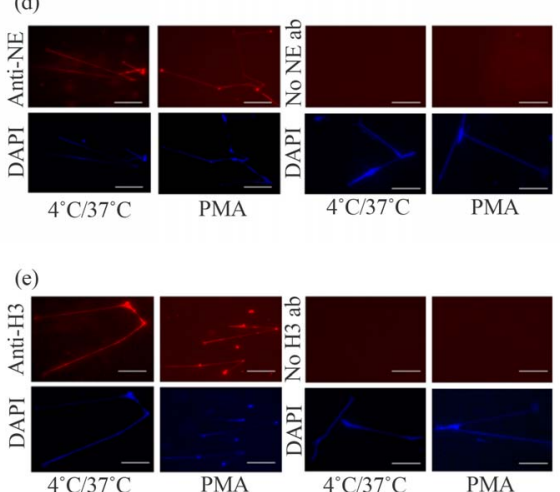

Figure 2. Hypothermia/rewarming-induced DAPI-positive objects exhibited several features similar to PMA-stimulated NETs. (a) Human neutrophils were incubated in a culture dish containing a coverslip at $4^{\circ} \mathrm{C}$ for $1 \mathrm{~h}$ followed by incubation at $37^{\circ} \mathrm{C}$ for $5 \mathrm{~h}$. The coverslip was removed and fixed in PBS containing $4 \%$ paraformaldehyde and then stained with DAPI (left). For the control, PMA-stimulated neutrophils, which exhibit canonical NETs, were fixed with $4 \%$ paraformaldehyde and subjected to DAPI-staining (right). Bar indicates $50 \mu \mathrm{m}$; (b) Human neutrophils were incubated in a culture dish containing a coverslip at $4^{\circ} \mathrm{C}$ for $1 \mathrm{~h}$ followed by incubation at $37^{\circ} \mathrm{C}$ for $5 \mathrm{~h}$. The coverslip was removed and then transferred to culture medium containing $E$. coli expressing recombinant GFP, followed by incubation for $15 \mathrm{~min}$ at $37^{\circ} \mathrm{C}$ (left). For the control, PMA-stimulated neutrophils were treated in the same way (right). The arrows indicate GFP-signals that represent $E$. coli. Bar indicates $50 \mu \mathrm{m}$; (c) After hypothermia/rewarming-(left) or PMA-incubation (right), the coverslips were treated with DNase buffer alone (gray bars) or DNase buffer containing $100 \mathrm{U} / \mathrm{ml}$ DNase I (black bars) at $37^{\circ} \mathrm{C}$ for $1 \mathrm{hr}$. The numbers of $E$. coli with GFP signals on the coverslips in the microscopic field $\left(0.35 \mathrm{~cm}^{2}\right)$ were counted. The values shown represent means \pm SE of three independent experiments; (d) The hypothermia/rewarming-induced DAPI-positive objects and PMAstimulated NETs were immunostained with (upper panels in left and middle-right columns) or without (upper panels in middle-right and right columns) anti-NE antibodies. DAPI-stained images of each treatment are shown at the bottom. Bar indicates $50 \mu \mathrm{m}$; (e) The hypothermia/rewarming-induced DAPI-positive objects and PMA-stimulated NETs were immunostained with (upper panels in left and middle-right columns) or without (upper panels in middle-right and right columns) anti-histone $\mathrm{H3}$ antibodies. DAPI-stained images of each treatment are shown at the bottom. Bar indicates $50 \mu \mathrm{m}$. 
elastase (NE) and anti-histone $\mathrm{H} 3$ antibodies [7]. As shown in Figures 2(d) and (e), in the presence of these anti-bodies, the signals were detected not only on PMAstimulated NETs but also on the DAPI-positive objects. In contrast, in the absence of the antibodies, these signals were barely detected, suggesting existence of NE and histone H3 on both the DAPI-positive objects and canonical NETs. Taken together, at least with regard to their ability to trap bacteria and the existence of two marker proteins for NETs, our results indicated that the DAPI-positive objects possessed biochemical similarities to canonical NETs.

It should be noted, however, the experiments described above are not sufficient to conclude that the DAPI-positive objects have anti-bacterial activity. We are therefore investigating whether NE and histones on the DAPIpositive objects can indeed inactivate bacterial toxic proteins, called "virulence factors," and inhibit bacterial growth. In addition, we wish to test whether the DAPIpositive objects can capture microorganisms besides Gram-negative bacteria (E. coli), such as fungi and parasites.

\subsection{The DAPI-Positive Objects Exhibited Several Biochemical Properties Different from Those of PMA-Stimulated NETs}

Although our results so far indicated a correlation between DAPI-positive objects and NETs, several differences were also revealed. For instance, when indirect immunofluorescence analysis was conducted using antihistone H3 citrulline R26 (anti-H3cit) antibody, we found that the antibody stained many, but not all, PMAstimulated NETs, whereas the antibody proved poor at detecting the DAPI-positive objects (Figure 3(a)). Because it has been reported that peptidylarginine deiminase 4 (PAD4/PADI4), which catalyzes histone hy per- citrullination, mediates chromatin decondensation and is vital to NET formation [13,20,21], our observation of different staining patterns with anti-H3cit antibody between the DAPI-positive objects and PMA-stimulated NETs implies activation of PAD4 in PMA-stimulated cells, while the enzyme might not be fully activated in the hypothermia/rewarming-treated cells.

We also detected differences between the objects and NETs in TUNEL assays. As shown in Figure 3(b), TUNEL-positive signals were negligible in PMA-treated cells, confirming the previous report that no TUNELpositive DNA damage is detectable in canonical NETs [15]. In contrast, TUNEL assay visualized more than $90 \%$ of the hypothermia/rewarming-induced DAPI-positive objects, indicating the existence of multiple sites of TUNEL-positive DNA damage on extensively unfolded DNAs in the objects. Because TUNEL-positive signals are frequently associated with apoptotic cells, these data indicated that hypothermia/rewarming-incubation might trigger, to some extent, activation of apoptosis-related DNA cleavage enzyme(s) in neutrophils, suggesting the possible contribution of apoptotic signaling pathways, at least in part, to DNA structural alterations during the formation of the DAPI-positive, NET-like structures.

\subsection{Involvement of ROS Elevation to Generate the DAPI-Positive Objects}

Given that ROS generation is an absolute requirement for the formation of NETs $[15,16]$, we next assessed whether hypothermia/rewarming of neutrophils coincided with the generation of ROS. Thus, we measured ROS in hypothermia/rewarming-treated human neutrophils. As shown in Figure 4(a), during constant temperature incubation at either $4^{\circ} \mathrm{C}$ or $37^{\circ} \mathrm{C}$, no increase/decrease in ROS was detected. In contrast, we found a significant elevation of ROS when cells were kept at $4^{\circ} \mathrm{C}$ followed

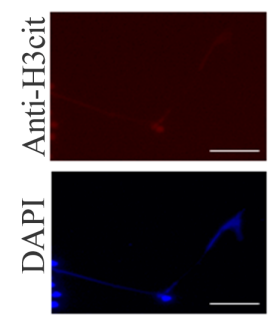

$4^{\circ} \mathrm{C} / 37^{\circ} \mathrm{C}$
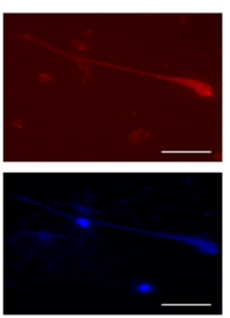

PMA

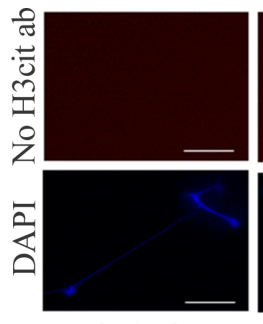

$4^{\circ} \mathrm{C} / 37^{\circ} \mathrm{C}$

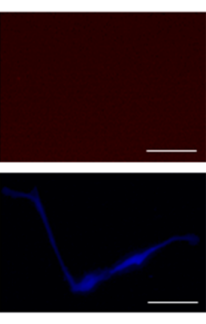

PMA

(a)

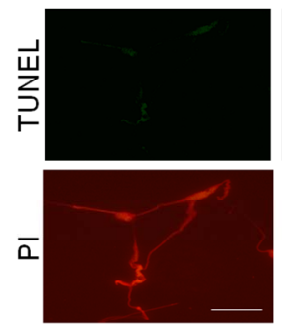

$4^{\circ} \mathrm{C} / 37^{\circ} \mathrm{C}$

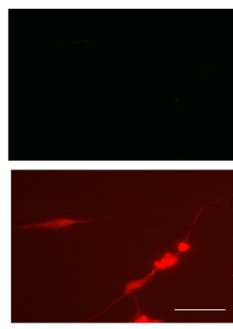

PMA

(b)

Figure 3. Hypothermia/rewarming-induced DAPI-positive, NET-like structures exhibited several features distinct from PMA-stimulated NETs. (a) The hypothermia/rewarming-induced DAPI-positive objects and PMA-stimulated NETs were immunostained with (upper panels in left and middle-right columns) or without (upper panels in middle-right and right columns) anti-H3cit antibodies. DAPI-stained images of each treatment are shown at the bottom. Bar indicates $50 \mu \mathrm{m}$; (b) $\mathrm{Hy}$ pothermia/rewarming-induced DAPI-positive, NET-like structures (left column) and PMA-stimulated NETs (right column) were subjected to TUNEL assay (upper panel). DNA was visualized with propidium iodide (PI; lower panel). Bar indicates 50 $\mu \mathrm{m}$. 


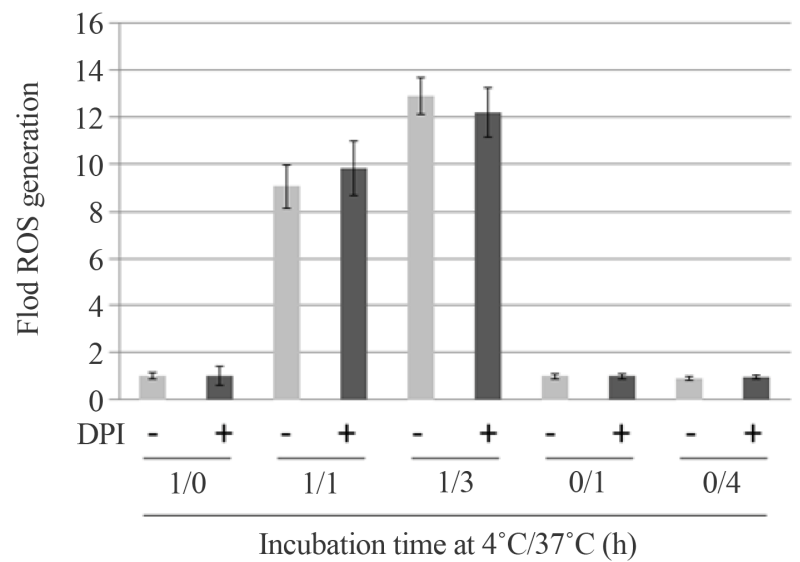

(a)

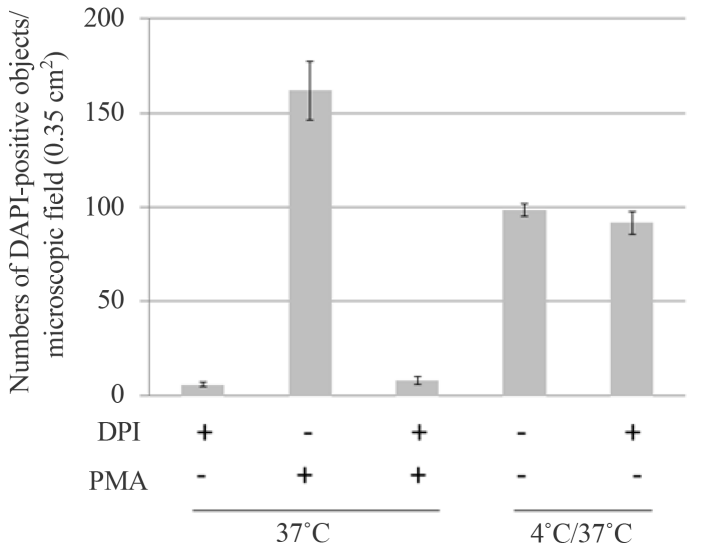

(b)

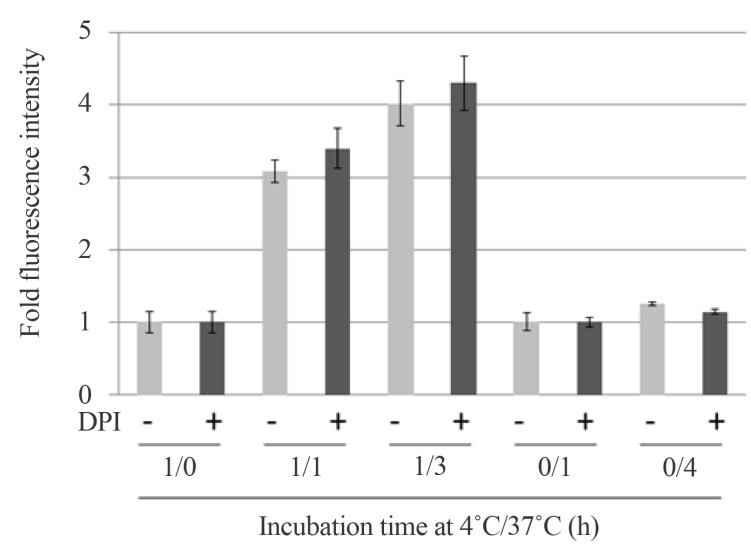

(c)

Figure 4. Hypothermia/rewarming-induced DAPI-positive, NET-like structures are biochemically and pharmacologically distinct from PMA-stimulated NETs. (a) Human neutrophils were incubated at $4^{\circ} \mathrm{C}$ for $1 \mathrm{~h}$ followed by incubation at $37^{\circ} \mathrm{C}$ for $1 \mathrm{~h}$ (indicated as " $1 / 1$ ") or $3 \mathrm{~h}$ (indicated as "1/3") in culture medium with (+; black bars) or without (-; gray bars) $20 \mu \mathrm{M}$ DPI. ROS formation by cells incubated at $4^{\circ} \mathrm{C}$ and $37^{\circ} \mathrm{C}$ was quantified using CellROX Deep Red Reagent and fold ROS generation ( $R O S$ formation at $37^{\circ} \mathrm{C}$ over that at $4^{\circ} \mathrm{C}$ ) was calculated. For the control, ROS formation was quantified during cell culture at $4^{\circ} \mathrm{C}$ for $1 \mathrm{~h}$ (indicated as "1/0") and $37^{\circ} \mathrm{C}$ for $1 \mathrm{~h}$ or $4 \mathrm{~h}$ (indicated as " $0 / 1$ " or " $0 / 4$ ", respectively) in the presence or absence of DPI, and fold ROS generation during each culture period (ROS formation at the start over that at the end of culture) was calculated; (b) Human neutrophils $\left(1 \times 10^{6}\right.$ cells) were incubated at $4^{\circ} \mathrm{C}$ for $1 \mathrm{~h}$ followed by incubation at $37^{\circ} \mathrm{C}$ for $5 \mathrm{~h}$ in culture medium with (black bars) or without (gray bars) $20 \mu \mathrm{M}$ DPI. The numbers of DAPI-positive objects on the coverslips in the microscopic field $\left(0.35 \mathrm{~cm}^{2}\right)$, which were in proportion to total numbers of the DAPI-positive objects in the cultures, were counted. For the control, human neutrophils were incubated at $37^{\circ} \mathrm{C}$ in the presence $(+)$ or absence $(-)$ of 20 $\mu M$ DPI or $50 \mathrm{nM}$ PMA and the numbers of NETs were counted; (c) Human neutrophils were incubated at $4^{\circ} \mathrm{C}$ for $1 \mathrm{~h}$ followed by incubation at $37^{\circ} \mathrm{C}$ for $1 \mathrm{~h}$ (indicated as "1/1") or $3 \mathrm{~h}$ (indicated as " $1 / 3$ ") in culture medium with (+; black bars) or without (-; gray bars) $20 \mu \mathrm{M}$ DPI. Cells were subjected to MitoTracker Red-staining and fold changes in fluorescent signals (signal at $37^{\circ} \mathrm{C}$ over that at $4^{\circ} \mathrm{C}$ ) were calculated. For the control, fluorescent signals were quantified during cell culture at $4^{\circ} \mathrm{C}$ for $1 \mathrm{~h}$ (indicated as " $1 / 0$ ") and $37^{\circ} \mathrm{C}$ for $1 \mathrm{~h}$ or $4 \mathrm{~h}$ (indicated as " $0 / 1$ " or " $0 / 4$ ", respectively) in the presence or absence of DPI, and fold fluorescent signal changes during each culture period (signal at the start over that at the end of culture) were calculated.

by incubation at $37^{\circ} \mathrm{C}$ for $1 \mathrm{~h}$ or $3 \mathrm{~h}$; an approximate 10 fold increase in ROS was apparent in the cells after incubation at $37^{\circ} \mathrm{C}$.

We next examined whether NADPH oxidase contributed to ROS production in hypothermia/rewarmingtreated cells. Given that PMA-induced NET formation is effectively inhibited by DPI, an inhibitor of NADPH oxidase activity $[15,17,18$ and see Figure 4(b)], we tested the effect of this drug. Intriguingly, neither ROS generation nor the formation of DAPI-positive objects was significantly affected by administration of DPI (Figures 4(a) and (b)), indicating that the mechanism of ROS generation in hypothermia/rewarming-treated neutrophils could be pharmacologically distinguished from that in PMA-stimulated cells with respect to the involvement of NADPH oxidase in ROS generation. 
Although where and how ROS are produced in the hypothermia/rewarming-treated cells remains unclear, it is noteworthy that the mitochondrion-specific dye, MitoTracker Red, detected structural and/or functional alterations in mitochondria in the hypothermia/rewarmingtreated cells (Figure 4(c)). Because mitochondria are known to produce ROS in aerobic organisms, including humans [22], these data suggest scenario that this organelle may generate ROS during hypothermia/rewarming, leading to the formation of the DAPI-positive, NET-like structures. However, DPI is also known as a potent inhibitor of mitochondrial reactive oxygen species production [23]. If DPI inhibits generation of ROS from both mitochondria and the NADPH oxidase pathway during hypothermia/rewarming of neutrophils, we need to consider the possibility of an alternative pathway to generate ROS, besides the NADPH oxidase pathway or the mitochondria pathway.

\section{Conclusion}

DAPI-positive objects with extensive DNA unfolding were observed in human neutrophils cultured in hypothermic conditions followed by rewarming. Our experimental data indicated that such DNA structural alterations in neutrophils may be related to NET formation, but can be biochemically and pharmacologically discriminated from NET formation. We also considered that the objects might not represent apoptotic cells, given that apoptotic cells contain condensed DNA enclosed in membrane, which is not observed in the objects. We thus suggest that the hypothermia/rewarming-induced DNA unfolding is regulated in a manner distinct from either canonical NETosis or canonical apoptosis, arguing the existence of a previously unappreciated signaling pathway that alters global genomic DNA structures in eukaryotic cells. Further, the results indicate that coldtreatment followed by warming may affect NET formation, which is an important consideration because many researchers use hypothermal conditions during the isolation and culture of neutrophils.

\section{Acknowledgements}

We thank all the members of the Saitoh Laboratory for helpful discussion. This work was supported by research grant to H. S. from Astellas Foundation for Research on Metabolic Disorders, and by intramural founding in $\mathrm{Ku}-$ mamoto Health Science University to J. K.

\section{REFERENCES}

[1] J. Kruuv, D. Glofcheski, K. H. Cheng, S. D. Campbell, H. M. Al-Qysi, W. T. Nolan and J. R. Lepock, "Factors Influencing Survival and Growth of Mammalian Cells Ex- posed to Hypothermia. I. Effects of Temperature and Membrane Lipid Perturbers," Journal of Cellular Physiology, Vol. 115, No. 2, 1983, pp. 179-185. doi:10.1002/jep.1041150212

[2] P. W. Hochachka, "Defense Strategies against Hypoxia and Hypothermia," Science, Vol. 231, No. 4735, 1986, pp. 234-241. doi:10.1126/science. 2417316

[3] N. Borregaard, "Neutrophils, From Marrow to Microbes," Immunity, Vol. 33, No. 5, 2010, pp. 657-670. doi:10.1016/j.immuni.2010.11.011

[4] B. Amulic, C. Cazalet, G. L. Hayes, K. D. Metzler and A. Zychlinsky, "Neutrophil Function: From Mechanisms to Disease," Annual Reviews: Annual Review of Immunology, Vol. 30, 2012, pp. 459-489. doi:10.1146/annurev-immunol-020711-074942

[5] V. Brinkmann, U. Reichard, C. Goosmann, B. Fauler, Y. Uhlemann, D. S. Weiss, Y. Weinrauch and A. Zychlinsky, "Neutrophil Extracellular Traps Kill Bacteria," Science, Vol. 303, No. 5663, 2004, pp. 1532-1535. doi:10.1126/science. 1092385

[6] B. E. Steinberg and S. Grinstein, "Unconventional Roles of the NADPH Oxidase: Signaling, Ion Homeostasis, and Cell Death," Science's STKE, Vol. 2007, No. 379, 2007, p. 11. doi:10.1126/stke.3792007pe11

[7] V. Brinkmann and A. Zychlinsky, "Neutrophil Extracellular Traps: Is Immunity the Second Function of Chromatin?" Journal of Cellular Physiology, Vol. 198, No. 5, 2012, pp. 773-783. doi:10.1083/jcb.201203170

[8] S. R. Clark, A. C. Ma, S. A. Tavener, B. McDonald, Z. Goodarzi, M. M. Kelly, K. D. Patel, S. Chakrabarti, E. McAvoy, G. D. Sinclair, E. M. Keys, E. Allen-Vercoe, R. Devinney, C. J. Doig, F. H. Green and P. Kubes, "Platelet TLR4 Activates Neutrophil Extracellular Traps to Ensnare Bacteria in Septic Blood," Nature Medicine, Vo. 13, No. 4, 2007, pp. 463-469. doi:10.1038/nm1565

[9] K. Kessenbrock, M. Krumbholz, U. Schönermarck, W. Back, W. L. Gross, Z. Werb, H. J. Gröne, V. Brinkmann and D. E. Jenne, "Netting Neutrophils in Autoimmune Small-Vessel Vasculitis," Nature Medicine, Vol. 15, No. 6, 2009, pp. 623-625. doi:10.1038/nm.1959

[10] G. S. Garcia-Romo, S. Caielli, B. Vega, J. Connolly, F. Allantaz, Z. Xu, M. Punaro, J. Baisch, C. Guiducci, R. L. Coffman, F. J. Barrat, J. Banchereau and V. Pascual, "Netting Neutrophils Are Major Inducers of Type I IFN Production in Pediatric Systemic Lupus Erythematosus," Science Translational Medicine, Vol. 3, No. 73, 2011, p. 73ra20. doi:10.1126/scitranslmed.3001201

[11] R. Lande, D. Ganguly, V. Facchinetti, L. Frasca, C. Conrad, J. Gregorio, S. Meller, G. Chamilos, R. Sebasigari, V. Riccieri, R. Bassett, H. Amuro, S. Fukuhara, T. Ito, Y. J. Liu and M. Gilliet, "Neutrophils Activate Plasmacytoid Dendritic Cells by Releasing Self-DNA-Peptide Complexes in Systemic Lupus Erythematosus," Science Translational Medicine, Vol. 3, No. 73, 2011, p. 73ra19. doi:10.1126/scitranslmed.3001180

[12] T. Saitoh, J. Komano, Y. Saitoh, T. Misawa, M. Takahama, T. Kozaki, T. Uehata, H. Iwasaki, H. Omori, S. Yamaoka, N. Yamamoto and S. Akira, "Neutrophil Extracellular Traps Mediate a Host Defense Response to 
Human Immunodeficiency Virus-1," Cell Host Microbe, Vol. 12, No. 1, 2012, pp. 109-116. doi:10.1016/j.chom.2012.05.015

[13] I. Neeli, N. Dwivedi, S. Khan and M. Radic, "Regulation of Extracellular Chromatin Release from Neutrophils," Journal of Innate Immunity, Vol. 1, No. 3, 2009, pp. 194201. doi: $10.1159 / 000206974$

[14] M. B. Lim, J. W. Kuiper, A. Katchky, H. Goldberg and M. Glogauer, "Rac2 is Required for the Formation of Neutrophil Extracellular Traps," Journal of Leukocyte Biology, Vol. 90, No. 4, 2011, pp. 771-776. doi:10.1189/jlb.1010549

[15] T. A. Fuchs, U. Abed, C. Goosmann, R. Hurwitz, I. Schulze, V. Wahn, Y. Weinrauch, V. Brinkmann and A. Zychlinsky, "Novel Cell Death Program Leads to Neutrophil Extracellular Traps," The Journal of Cell Biology, Vol. 176, No. 2, 2007, pp. 231-241. doi:10.1083/jcb.200606027

[16] M. Bianchi, A. Hakkim, V. Brinkmann, U. Siler, R. A. Seger, A. Zychlinsky and J. Reichenbach, "Restoration of NET Formation by Gene Therapy in CGD Controls Aspergillosis," Blood, Vol. 114, No. 13, 2009, pp. 26192622. doi:10.1182/blood-2009-05-221606

[17] A. Hakkim, T. A. Fuchs, N. E. Martinez, S. Hess, H. Prinz, A. Zychlinsky and H. Waldmann, "Activation of the Raf-MEK-ERK Pathway Is Required for Neutrophil Extracellular Trap Formation," Nature Chemical Biology, Vol. 7, No. 2, 2011, pp. 75-77. doi: $10.1038 /$ nchembio. 496

[18] B. V. O’Donnell, D. G. Tew, O. T. Jones and P. J. Eng- land, "Studies on the Inhibitory Mechanism of Iodonium Compounds with Special Reference to Neutrophil NADPH Oxidase," Biochemical Journal, Vol. 290, No. 1, 1993, pp. 41-49.

[19] Q. Remijsen, T. Vanden Berghe, E. Wirawan, B. Asselbergh, E. Parthoens, R. De Rycke, S. Noppen, M. Delforge, J. Willems and P. Vandenabeele, "Neutrophil Extracellular Trap Cell Death Requires Both Autophagy and Superoxide Generation," Cell Research, Vol. 21, No. 2, 2011, pp. 290-304. doi:10.1038/cr.2010.150

[20] I. Neeli, S. N. Khan and M. Radic, "Histone Deimination as a Response to Inflammatory Stimuli in Neutrophils," The Journal of Immunology, Vol. 180, No. 3, 2008, pp. 1895-1902.

[21] Y. Wang, M. Li, S. Stadler, S. Correll, P. Li, D. Wang, R. Hayama, L. Leonelli, H. Han, S. A. Grigoryev, C. D. Allis and S. A. Coonrod, "Histone Hypercitrullination Mediates Chromatin Decondensation and Neutrophil Extracellular Trap Formation," The Journal of Cell Biology, Vol. 184, No. 2, 2009, pp. 205-213. doi:10.1083/jcb.200806072

[22] M. Maryanovich and A. Gross, "A ROS Rheostat for Cell Fate Regulation," Trends in Cell Biology, Vol. 23, No. 3, 2013, pp. 129-134. doi:10.1016/j.tcb.2012.09.007

[23] L. Yunbo and A. Michael, "Diphenyleneiodonium, an NAD(P)H Oxidase Inhibitor, Also Potently Inhibits Mitochondrial Reactive Oxygen Species Production," Biochemical and Biophysical Research Communications, Vol. 253, No. 2, 1998, pp. 295-299.

doi:10.1006/bbrc.1998.9729 